\title{
Effect of N-glycosylation inhibition on the synthesis and processing of classical swine fever virus glycoproteins
}

\author{
Jolanta Tyborowska ${ }^{\bowtie}$, Ewa Zdunek and Bogusław Szewczyk \\ Department of Molecular Virology, Intercollegiate Faculty of Biotechnology, University of Gdansk, \\ and Medical University of Gdansk, Gdansk, Poland
}

Received: 17 July, 2007; revised: 07 November, 2007; accepted: 03 December, 2007

available on-line: 17 December, 2007

\begin{abstract}
Classical swine fever virus (CSFV) is often used as a surrogate model in molecular studies of the closely related hepatitis $C$ virus. In this report we have examined the effect of the inhibition of glycosylation on the survival and maturation of CSFV. Viral glycoproteins ( $E^{\text {rns }, ~ E 1, ~ E 2) ~ f o r m ~}$ biologically active complexes - homo- and heterodimers, which are indispensable for viral life cycle. Those complexes are highly $\mathrm{N}$-glycosylated. We studied the influence of $\mathrm{N}$-glycosylation on dimer formation using $\mathrm{E}^{\text {rns }}$ and $\mathrm{E} 2$ glycoproteins produced in insect cells after infection with recombinant baculoviruses. The glycoproteins were efficiently synthesized in insect cells, had similar molecular masses and formed dimers like their natural counterparts. Surprisingly, the addition of tunicamycin (an antibiotic which blocks early steps of glycosylation) to insect cell culture blocked not only dimer formation but it also led to an almost complete disappearance of E2 even in monomeric form. Tunicamycin did not exert a similar effect on the synthesis and formation of $\mathrm{E}^{\mathrm{rns}}$ dimers; the dimers were still formed, which suggests that $\mathrm{E}^{\text {rns }}$ glycan chains are not necessary for dimer formation. We have also found that very low doses of tunicamycin (much lower than those used for blocking N-glycosylation) drastically reduced CSFV spread in SK6 (swine kidney) cell culture and the virus yield. These facts indicate that N-glycosylation inhibitors structurally similar to tunicamycin may be potential therapeutics for the inhibition of the spread of CSFV and related viruses.
\end{abstract}

Keywords: pestivirus, classical swine fever virus, glycoproteins, glycosylation

\section{INTRODUCTION}

Classical swine fever virus (CSFV) belongs to the genus Pestivirus, family Flaviviridae. It causes a highly contagious disease in pigs, which is characterized by high morbidity and mortality. CSFV shares many similarities with hepatitis $\mathrm{C}$ virus (HCV), one of the most important human pathogens of the last two decades. Most of the proteins of these two viruses are functionally homologous, so in the absence of a widely available system for propagation of $\mathrm{HCV}, \mathrm{CSFV}$ often serves as HCV surrogate model for molecular studies.
CSFV is an enveloped, single-stranded RNA $(+)$ virus. Its genome $(12.3 \mathrm{~kb}$ in size $)$ encodes a single polyprotein precursor (3898 aa) which is processed by host and viral proteases into mature structural and nonstructural proteins. The structural proteins include nucleocapsid protein $C$ and three envelope glycoproteins: E0 ( $\left.\mathrm{E}^{\mathrm{rns}}\right), \mathrm{E} 1$ and E2. The CSFV glycoproteins in the viral envelope and infected cells are present in the form of biologically active disulfide-bonded homo- and heterodimers (Weiland et al., 1990; Thiel et al., 1991; Rumenapf et al., 1993). The $\mathrm{E}^{\mathrm{rns}}$ and $\mathrm{E} 2-\mathrm{E} 1$ complexes are involved in interactions with host cells during virus

${ }^{\square}$ Corresponding author: Jolanta Tyborowska, Department of Molecular Virology, Intercollegiate Faculty of Biotechnology, University of Gdańsk, Kładki 24, 80-822 Gdańsk, Poland; tel.: (48) 58523 6382; fax: (48) 58 305 7312; e-mail: jtybor@biotech.ug.gda.pl

Abbreviations: CSFV, classical swine fever virus; $E^{\text {rns }, ~ E 1, ~ E 2, ~ v i r a l ~ e n v e l o p e ~ g l y c o p r o t e i n s ; ~ E R, ~ e n d o p l a s m i c ~ r e t i c u l u m ; ~}$ $\mathrm{HCV}$, hepatitis C virus; IPMA, immunoperoxidase monolayer assay; mAb, monoclonal antibody; MOI, multiplicity of infection; PBS, phosphate-buffered saline; SK6, swine kidney cells. 
entry and cell-to-cell spread (Hulst \& Moormann, 1997). They are the main virulence factors and the main targets for the host immune response (Weiland et al., 1990). E2 exists mostly as a heterodimer with glycoprotein E1 (molecular mass of the dimer about $75 \mathrm{kDa}$ ); only a small fraction of E2 forms homodimers (molecular mass about $100 \mathrm{kDa}$ ). Both E2 and E1 contain transmembrane domains. E2 is the most immunogenic viral protein and is the major target for neutralizing antibodies. $\mathrm{E}^{\mathrm{rns}}$ is the second target for neutralizing antibodies; it exists as a homodimer (molecular mass about $97 \mathrm{kDa}$ ) which is present in virions, on the surface of infected cells and is also secreted from the cell (Thiel et al., 1991). $E^{\text {rns }}$ lacks the membrane anchor and probably is bound to the virus envelope and cell surface by hydrophobic interactions (Weiland et al., 1999). E $\mathrm{E}^{\text {rns }}$ is the only known viral surface protein which has an RNase activity (Schneider et al., 1993). Secreted $\mathrm{E}^{\mathrm{rns}}$ is suspected to be a factor causing apoptosis of lymphocytes leading to immunosupression (Hulst et al., 1994; Wildish et al., 1995).

E2 contains six potential N-glycosylation sites, $E^{\text {rns }}$ contains nine such sites and the positioning of $\mathrm{N}$-linked glycans is conserved among viral strains. $\mathrm{N}$-glycosylation is an important step for protein maturation and functioning (Risatti et al., 2007). The sugar moieties assist in proper folding, stabilize protein conformation, make proteins more resistant to protease degradation and more hydrophilic. Viral particles covered with sugars produced by host machinery are less efficiently recognized by the immune system (Scanlan et al., 2007). Alterations of the glycosylation by specific inhibitors have usually an anti-viral effect (Leavitt et al., 1977; Mehta et al., 1998; Parodi, 2000)

$\mathrm{N}$-glycosylation occurs cotranslationally; in this process a 14-residue oligosaccharide core unit (Glc3Man9GlcNAc2) is transferred by oligosaccharyl transferase from dolichol pyrophosphate to an asparagine side chain (consensus sequence Asn-XaaSer/Thr) of the nascent polypeptides (Imperiali et al., 1999). This step of N-glycosylation can be blocked by an antibiotic tunicamycin (Elbein, 1987). Lack of Nglycan chains can lead to protein miss-folding causing their aggregation in ER or degradation (Parodi, 2000; Trombetta, 2003; Jones et al., 2005, Indyk et al., 2007).

In this report we describe our studies on the contribution of the N-glycosylation to the dimerization of CSFV glycoproteins and its influence on viral propagation. We have studied effect of tunicamycin on those processes by two experimental approaches - using swine kidney cells SK6, which support propagation of CSFV, and using isolated $\mathrm{E}^{\text {rns }}$ and E2 glycoproteins produced in a heterologous baculovirus system.

\section{MATERIALS AND METHODS}

Cells. SK6 (swine kidney) cells were grown in EMEM (Sigma) supplemented with 5\% FBS.

Sf9 (Spodoptera frugiperda) insect cells were grown in HyQ-SFX medium (Hyclone).

Viruses. CSFV Cellpest (a vaccine strain, derivative of C-strain, obtained from Tomasz Stadejek from the National Veterinary Institute in Puławy, Poland) was used for the experiments.

Autographa californica nuclear polyhedrosis virus (AcNPV) recombinants expressing full-length form of $E^{\text {rns }}$ or full-length form of E2 were used for the dimerization studies. To obtain recombinant baculoviruses, cDNAs coding for full length E2 and $\mathrm{E}^{\text {rns }}$ of CSFV were introduced into baculovirus transfer vector $\mathrm{pFastBac}$ and baculoviruses expressing E2 and $E^{\text {rns }}$ were generated by transposition-mediated recombination using the "Bac-to-Bac system" from Invitrogen (Luckow et al., 1993).

Antibodies. Anti-E2 mAb 24/10, rabbit polyclonal serum anti-E2, rabbit polyclonal serum anti$E^{\text {rns }}$ were used. Secondary antibody conjugates, goat anti-rabbit-alkaline phosphatase (AP), goat anti-rabbit-horse radish peroxidase (HRPO) and rabbit antimouse-AP were purchased from Santa-Cruz Biotechnology (USA). Fluorescence goat anti-rabbit and goat anti-mouse conjugates with Alexa dyes were purchased from Molecular Probes (USA).

Western blot analysis of baculovirus-infected insect cells expressing $E^{\text {rns }}$ and E2. For detection of E2 and $E^{\text {rns }}$ in insect cells and studies of the effect of tunicamycin on dimer formation, Sf9 cells grown on a 12-well plate were infected with recombinant baculoviruses at multiplicity of infection (MOI) of 10. Two hours later the inoculum was removed and replaced with fresh medium. For blocking N-glycosylation medium containing different doses of tunicamycin was used. Three days post infection cells were harvested, washed with PBS and whole cells were subjected to SDS/PAGE, or they were separated into soluble and insoluble fraction by lysis (for $10 \mathrm{~min}$ on ice) in equal volumes of $0.03 \mathrm{M}$ Tris/ $\mathrm{HCl}$ $+0.01 \mathrm{M}$ magnesium acetate $+1 \%$ Nonidet $\mathrm{P}-40, \mathrm{pH}$ 7.5. The lysates were centrifuged at $13000 \mathrm{rpm}$ for $20 \mathrm{~min}$, supernatants (soluble fractions) were collected and pellets (insoluble fractions) were washed twice with PBS and then resuspended in PBS to the same volume as the collected soluble fractions. Samples were subjected to SDS/PAGE under non-reducing conditions. After electrophoresis proteins were transferred to PVDV membranes. Membranes were first incubated with specific $\mathrm{mAb}$ anti-E2 or polyclonal sera anti- $E^{\text {rns }}$ and then with alkaline phosphatase-conjugated secondary antibodies. NBT and BCiP substrates were used for visualization of reaction with antibodies. 
Western blot analysis of CSFV-infected swine kidney cells SK6. SK6 cells were grown in EMEM + 5\% FBS, and infected with CSFV Cellpest at MOI 1. Two hours after infection the medium was changed for EMEM supplemented with different doses of tunicamycin. Three days post infection the cells were harvested, washed with PBS, lysed in non-reducing SDS/PAGE sample buffer and subjected to electrophoresis followed by immunoblotting. This was performed in the same way as described for insect cells.

Cell viability assay. CSFV-infected and noninfected cells were grown in the absence or presence of different doses of tunicamycin. After 2 days the cells were trypsinized, spinned down, washed with PBS and combined with cells recovered from the growth media. Cells resuspended in PBS were stained with $0.1 \%$ trypan blue (dead cells are stained) and viable cells and dead cells were counted under the microscope using Thoma's chamber.

Plaque and yield reduction assay. SK6 cells were grown to subconfluent monolayers in 12-well plates and infected with CSFV-Cellpest at a MOI of 0.005 for $2 \mathrm{~h}$ at $37^{\circ} \mathrm{C}$. After removal of the inoculum, fresh medium containing different concentrations of tunicamycin was added and cultures were incubated for 3 days. The medium containing virus was then collected from wells and centrifuged. Cells were washed with PBS and fixed for $10 \mathrm{~min}$ with cold $40 \%$ acetone in $0.5 \times$ PBS. Fixed cells were dried and washed with PBS. Immunoperoxidase monolayer assay (IPMA) was used for detection of CSFV plaques and was performed using rabbit polyclonal serum to $E^{\text {rns }}$ or to E2 diluted in PBS containing 1\% Tween 20 and $5 \%$ FBS. After $1 \mathrm{~h}$ incubation, cells were washed three times with PBS containing 1\% Tween 20 and then they were incubated for $1 \mathrm{~h}$ with goat anti-rabbit antibody-HRPO conjugate. Cells were washed again three times and antibody complexes were detected using $\mathrm{H}_{2} \mathrm{O}_{2} / \mathrm{AEC}$ (3-amino-9-ethylcarbazole from Sigma) which gives red precipitates enabling quantification of plaques and comparison of their size.

Collected medium was used to infect fresh monolayers of SK6 cells in 12-well plates (in ten-fold dilutions) for counting the virus yield. Two days after infection cells were fixed and plaques were visualized as described above.

Indirect immunofluorescence and confocal imaging. Subconfluent SK6 cells grown in 12well plates on coverslips were infected with CSFVCellpest at a MOI of 0.01. After two hours the inoculum was removed and fresh medium containing different concentrations of tunicamycin was added. At $16 \mathrm{~h}$ post infection the cells were fixed with $4 \%$ paraformaldehyde in PBS for $20 \mathrm{~min}$. Cells were permeabilized with $0.5 \%$ Triton X-100 in PBS for 15 min or left intact for surface staining. Cells were incubated with primary antibodies in PBS for $1 \mathrm{~h}$. They were then washed three times with PBS and incubated for $1 \mathrm{~h}$ with Alexa-conjugated secondary antibodies. After three washes, coverslips were mounted on microscopic slides and studied for the localization of E2 and $E^{\text {rns }}$ glycoproteins using a Nikon laser-scanning confocal microscope PCM-2000.

\section{RESULTS AND DISCUSSION}

\section{Characterization of $E^{\text {rns }}$ and E2 expressed in baculo- virus system}

It is an established fact that glycosylation inhibitors may have an inhibitory effect on the propagation of many viruses (Leavitt et al., 1977; Mehta et al., 1998; Parodi, 2000). Flaviviruses are not an exception to this rule and their propagation is affected by some glycosylation inhibitors. The aim of our investigations was to characterize the contribution of $\mathrm{N}$-glycosylation to the synthesis and maturation of CSFV glycoproteins. In the initial stage of our studies we tested the effect of glycosylation status on the formation of E2 and $E^{\text {rns }}$ dimers in an isolated system. For this purpose the baculovirus expression system was chosen because the post-translational modifications in insect cells are similar to those in mammalian cells. Additionally, it is a versatile system giving high level expression of foreign genes (Miller, 1993). It is widely used for production of vi-

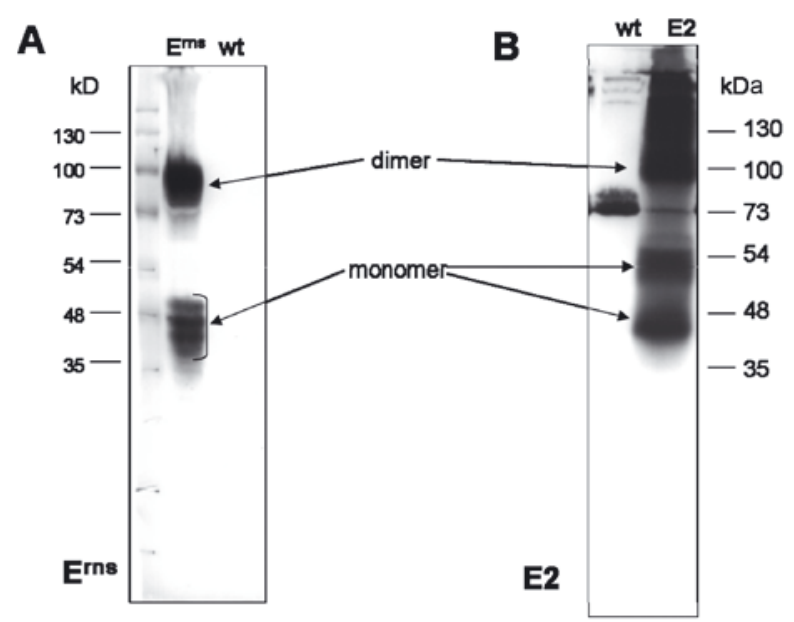

Figure 1. Expression of CSFV $\mathrm{E}^{\mathrm{rns}}$ and E2 in baculovirus system.

Whole cell lysates were separated by $10 \%$ SDS/PAGE under non-reducing conditions. Negative control (lanes: Wt) - lysate of cells infected with wild type baculovirus.. Panel A. Immunodetection of $\mathrm{E}^{\text {rns }}$ with rabbit polyclonal anti- $E^{\text {rns }}$ serum. Arrows indicate monomers and dimers. Panel B. Immunodetection of E2 with mAb 24/10, arrows indicate dimer and glycosylated and nonglycosylated monomers. 
ral proteins in a biologically active form and allows for studies of the formation of different protein complexes in an isolated system in the absence of native parental virions. Previously it was successfully used by us for the characterization of glycoprotein complexes of pseudorabies virus and bovine herpesvirus type 1 (Tyborowska et al., 2000; 2006).

In these studies, we constructed baculovirus recombinants expressing full-length forms of $E^{\text {rns }}$ and E2 of CSFV. The expression of $E^{\text {rns }}$ and E2 in insect cells and formation of homodimers (which in natural host cells are stabilized by disulfide bonds) was tested under non-reducing conditions by Western blot analysis. E2 and $\mathrm{E}^{\mathrm{rns}}$ were expressed efficiently in insect cells and were mostly present as homodimers (Fig. 1A and B). Although some aggregates of higher molecular mass were also present, the bands corresponding to monomers and dimers of E2 and Erns expressed in insect cells exhibited molecular masses similar to their natural counterparts.

Effect of tunicamycin on the synthesis and dimer formation of CSFV $E^{\text {rns }}$ and E2 glycoproteins in insect cells

We tested the influence of N-glycans on E2 and $E^{\text {rns }}$ homodimer formation and their cellular localization by using the antibiotic tunicamycin, which blocks early stages of N-glycosylation. For this purpose insect cells infected with respective baculoviruses were grown in the presence of different doses of tunicamycin. Infected cells were fractionated using mild lysis, which results in a soluble fraction (cytoplasmic proteins and some membrane proteins) and an insoluble fraction (mostly membranes). The results obtained by Western blotting (Fig. 2A) showed that deglycosylated $\mathrm{E}^{\text {rns }}$ was still able to form dimers, but the deglycosylated $\mathrm{E}^{\text {rns }}$ dimer and monomer and higher molecular aggregates were present only in the insoluble fraction (membrane fraction), while $\mathrm{E}^{\mathrm{rns}}$ produced without tunicamycin (therefore glycosylated) was present mostly in the soluble fraction. This suggests, that glycan chains are not critical for $\mathrm{E}^{\mathrm{rns}}$ dimerization but they are important for its proper maturation and transport; it is likely that deglycosylated $\mathrm{E}^{\text {rns }}$ aggregates and is retained in the ER.

To our surprise, the addition of tunicamycin to insect cells infected with E2-expressing baculovirus blocked not only dimer formation but it led to the complete disappearance of E2 even in the monomeric form (Fig. 2B). This effect is unique because usually deglycosylated viral glycoproteins are stable. This fact suggests that E2 lacking N-glycans is very unstable and is very quickly degraded. It was reported in the past that modification of two glycosylation sites in E2 of related bovine diarhorea virus (BVDV) impaired expression and secretion of the protein in insect cells, suggesting that glycosylation is essential for correct folding of E2 (Pande et al., 2005).

\section{Effect of tunicamycin concentration on the propaga- tion of CSFV-Cellpest and survival of SK6 cells}

Because of the destructive effect of tunicamycin on E2 in insect cells, we decided to test whether tunicamycin inhibited propagation of CSFV in porcine cells. For this purpose SK6 cells were infected with CSFV vaccine strain Cellpest and the effect of different doses of tunicamycin on virus propagation and cell survival was examined. Standard concentrations of tunicamycin used for deglycosylation studies are usually in the range of 0.5 to $4 \mu \mathrm{g}$ per mililiter of medium while the concentrations used in our experiments and their effect on the cell viability and virus propagation are summarized in Table 1 . The survival rate was measured by trypan blue staining after $48 \mathrm{~h}$ and it was dependent on

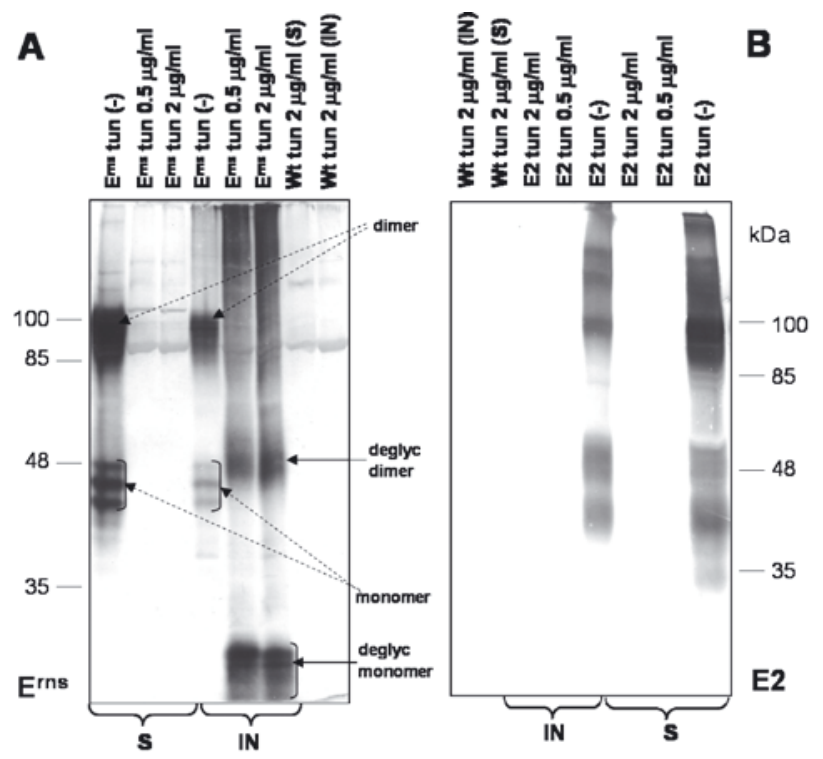

Figure 2. Effect of tunicamycin on the synthesis and dimer formation of CSFV $E^{\text {rns }}$ and E2 glycoproteins in insect cells.

Baculovirus-infected insect cells were grown for $72 \mathrm{~h}$ in the presence of $0.5 \mu \mathrm{g} / \mathrm{ml}$ or $2 \mu \mathrm{g} / \mathrm{ml}$ of tunicamycin. Infected cells $\left(10^{6}\right)$ were separated into soluble (S) and insoluble (IN) fractions using equal volumes of lysis buffer. Equal volumes of the fractions were subjected to SDS/PAGE and immunodetection as described in Fig. 1. Negative controls: lane Wt (S) or Wt (IN), fractions of cells infected with wild type baculovirus. Positive controls: fractions of infected cells expressing $\mathrm{E}^{\text {rns }}$ or E2 grown without tunicamycin (tun (-)). Panel A. Expression of $E^{\text {rns }}$ in the presence of tunicamycin. Arrows indicate glycosylated and deglycosylated (deglyc) forms of $\mathrm{E}^{\mathrm{rns}}$ monomers or dimers. Panel B. Expression of E2 in the presence of tunicamycin, lack of expression. 
Table 1. Effect of tunicamycin concentration on the propagation of CSFV-Cellpest and survival of SK6 cells.

CSFV-infected cells were grown in the presence of different doses of tunicamycin in medium containing either $2 \%$ or $8 \%$ fetal bovine serum. Cell viability was determined by trypan blue staining. Virus titer was determined as described in Materials and Methods. ND, not determined, virus titer was not tested because of excessive cell death.

\begin{tabular}{lcccc}
\hline $\begin{array}{l}\text { Tunicamy- } \begin{array}{l}\text { Cell sur- } \\
\text { vival [\%] } \\
\text { cin dose } \\
\text { EMEM+2\%FBS }\end{array} \\
2 \mu \mathrm{rg}\end{array}$ & $\begin{array}{l}\text { Titer of } \\
\text { virus }\end{array}$ & $\begin{array}{l}\text { Cell sur- } \\
\text { vival [\%] } \\
\text { EMEM+8\%FBS }\end{array}$ & $\begin{array}{l}\text { Titer of } \\
\text { virus }\end{array}$ \\
\hline $1 \mu \mathrm{g}$ & 0 & $\mathrm{ND}$ & 10 & $\mathrm{ND}$ \\
$500 \mathrm{ng}$ & 0 & $\mathrm{ND}$ & 30 & $\mathrm{ND}$ \\
$250 \mathrm{ng}$ & 25 & $\mathrm{ND}$ & 50 & $\mathrm{ND}$ \\
$125 \mathrm{ng}$ & 50 & $\mathrm{ND}$ & 85 & $3 \times 10^{3}$ \\
$62.5 \mathrm{ng}$ & 90 & $3 \times 10^{3}$ & 95 & $4 \times 10^{4}$ \\
$31.2 \mathrm{ng}$ & 98 & $5 \times 10^{4}$ & 98 & $4 \times 10^{6}$ \\
& & & & \\
0 & 98 & $4 \times 10^{6}$ & 98 & $4 \times 10^{6}$ \\
\hline
\end{tabular}

the concentration of serum in the medium (higher concentrations of serum promote survival of cells). It follows from this experiment that tunicamycin is much more toxic to swine kidney cells than to insect cells and the concentrations used for deglycosylation studies were toxic to SK6 cells (most of them were dead already after $24 \mathrm{~h}$ of incubation with tunicamycin).

CSFV strain Cellpest is noncytopathogenic, therefore the foci of infected cells (pseudo-plaques) were detected by immunoperoxidase monolayer assay. We found that CSFV pseudo-plaques formed in the presence of very low concentrations of tunicamycin (which were not toxic) - $62.5 \mathrm{ng} / \mathrm{ml}$ (cell viability $90 \%$ ) and $31.2 \mathrm{ng} / \mathrm{ml}$ (cell viability 98\%), were very small (suggesting inhibition of virus cellto-cell spread) compared to the control and that the virus yield was reduced, respectively, about 1000× and 100x. This means that very low concentrations of tunicamycin (non-toxic to the very sensitive mammalian cells) blocked CSFV propagation very effectively (Table 1).

Effect of tunicamycin on synthesis of CSFV glycoproteins and E2-E1 heterodimer formation in SK6 cells

In cells infected with CSFV, most of the E2 glycoprotein is present as a heterodimer formed by disulfide bonds with E1. Because tunicamycin in low doses effectively blocked virus propagation we tested whether E2-E1 heterodimer formation was affected in these conditions. This was done by Westernblotting (Fig. 3) and the results of this experiment show that low doses of tunicamycin did not affect E2-E1 heterodimer formation. $E^{\text {rns }}$ dimerization was not affected either (not shown).

\section{In situ analysis of localization of CSFV glycopro-} teins in SK6 cells

Using confocal microscopy we examined the localization of E2 and $E^{\text {rns }}$ in SK6 cells infected with CSFV in the presence of low doses of tunicamycin. Cells growing on coverslips had to be treated with even lower doses of tunicamycin than those used in the above studies because they detached in the presence of higher tunicamycin concentrations. Even at the concentration of $12 \mathrm{ng} / \mathrm{ml}$ of tunicamycin the foci of infected cells were smaller (Fig. 4) than for the control without tunicamycin; it was observed that transport of $E^{\text {rns }}$ to the surface was blocked (lack of surface staining - Fig. 4D). In addition the localization of $\mathrm{E}^{\mathrm{rns}}$ inside the cell was changed (Fig. 4C). It has been reported that $\mathrm{E}^{\mathrm{rns}}$ interacts with heparan sulfate on the cell surface during the initial binding of the virus facilitating endocytosis of the viral particle (Hulst et al., 1994). Retroviral pseudotype studies have shown that E2-E1 heterodimer is sufficient for the infectivity of pseudoparticles and $\mathrm{E}^{\text {rns }}$ of CSFV is not needed (Wang et al., 2004), but CSFV mutants lacking $E^{\text {rns }}$ are not infectious and have to be grown on an $E^{\text {rns }}$-complementing cell line (Frey et al., 2006). It is very likely that in natural CSFV infection, the presence of $E^{\text {rns }}$ on the viral envelope and on the cell surface is essential for proper virus maturation, its assembly, egress and cell-to-cell spread.

No changes of the localization of E2 in SK6 cells were observed in the analogous conditions be-

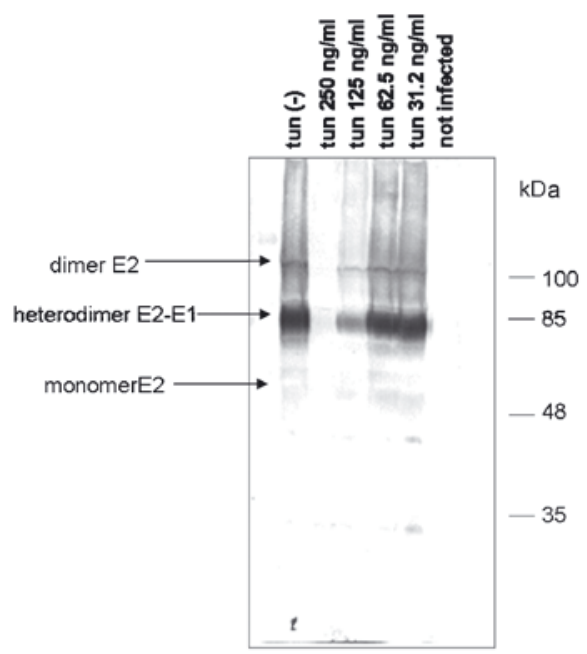

Figure 3. Effect of tunicamycin on synthesis of CSFV glycoproteins and E2-E1 heterodimer formation in SK6 cells.

SK6 cells infected with CSFV-Cellpest were grown in the presence of different doses of tunicamycin for $72 \mathrm{~h}$. Whole cell lysates were separated by $10 \%$ SDS/PAGE under nonreducing conditions. Negative control, non-infected cells. Positive control, infected cells grown without tunicamycin (tun(-)). Immunodetection was performed with mAb 24/10 anti-E2. Arrows indicate E2 monomer, E2 dimer and E2E1 heterodimer. 
Total
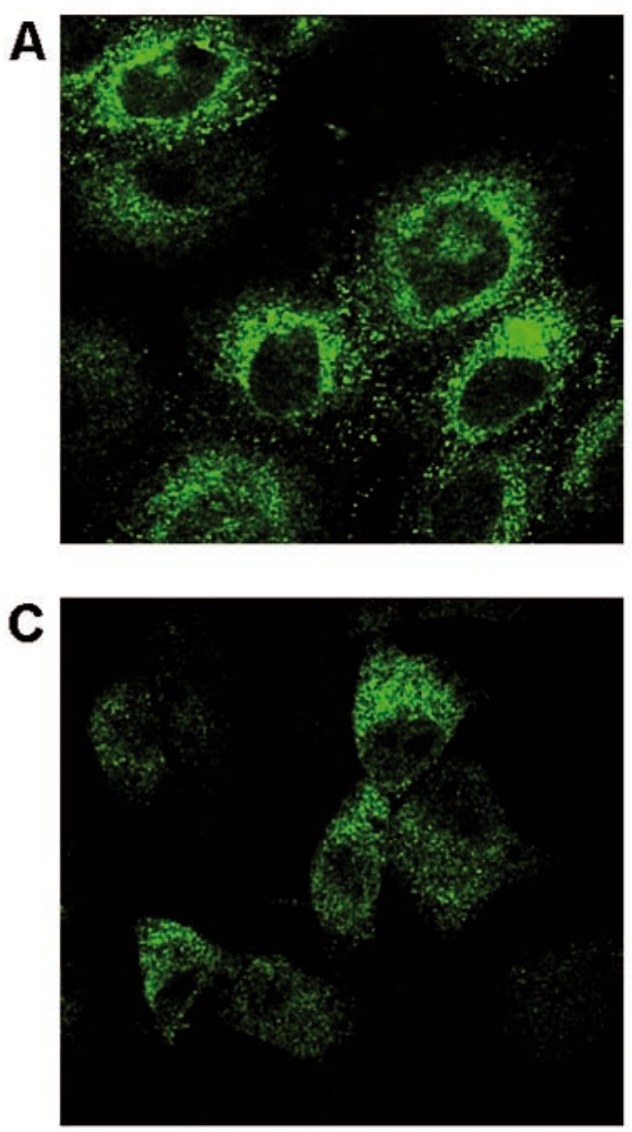

Surface
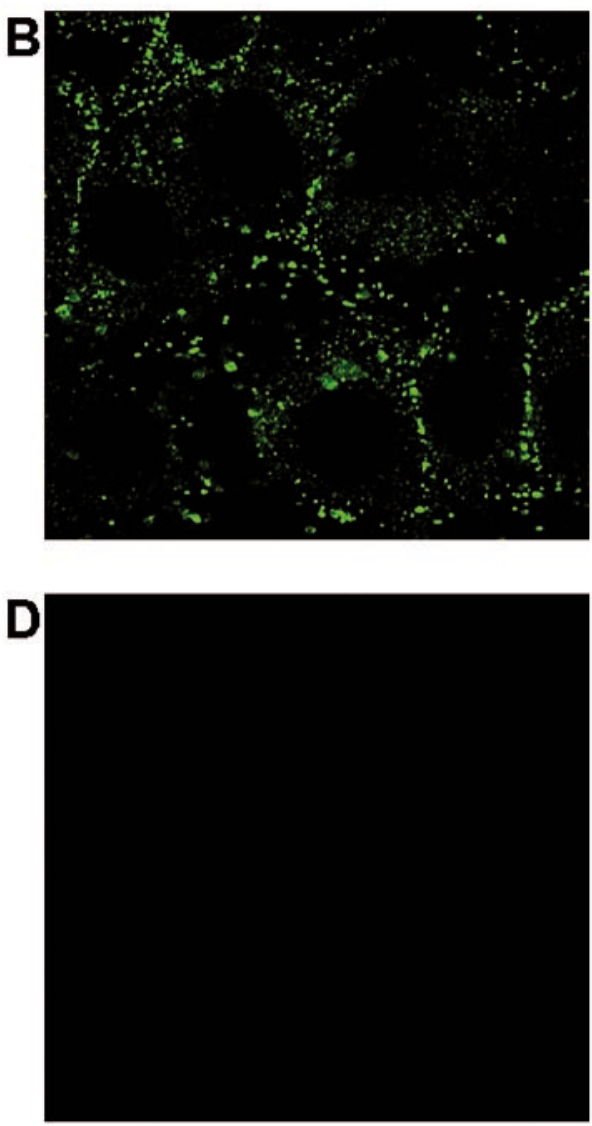

\section{No treatment}

\section{tunicamycin}

Figure 4. Effect of tunicamycin on localization of $E^{\text {rns }}$ in CSFV-infected SK6 cells.

Sixteen hours after infection with CSFV SK6 cells were fixed and permeabilized with $0.5 \%$ Triton X-100 or left intact for surface staining. $\mathrm{E}^{\mathrm{rns}}$ localization was visualized with Alexa 488 dye conjugated to goat IgG. A and B, control cells grown without tunicamycin. $\mathrm{C}$ and $\mathrm{D}$, cells grown in the presence of $12 \mathrm{ng} / \mathrm{ml}$ tunicamycin.

cause during natural infection E2 is retained in ER and the presence of tunicamycin does not change its localization (not shown). But taking into account our results from the expression of $\mathrm{E} 2$ in insect cells it is very likely that the E2-E1 homodimer formed in the presence of low concentrations of tunicamycin loses its biological activity.

Our results may indicate that the observed effect of inhibition of CSFV propagation by low doses of tunicamycin may be caused by some other mechanisms than N-glycosylation inhibition. It has been reported that low doses of tunicamycin affect cellular receptors and signal transduction (Mauro et al., 2003; Horikawa et al., 2006) and these effects may inhibit proper transport of viral components and virus maturation.

\section{CONCLUSIONS}

Summarizing our results, we have shown that tunicamycin abolishes effective production of E2 in insect cells, probably leading to its degradation. Deglycosylated $E^{\text {rns }}$ produced in insect cells forms dimers but its transport is affected, it is completely retained in the insoluble fraction (most likely in the ER compartment).

In the presence of very low doses of tunicamycin during infection of mammalian cells with CSFV, $\mathrm{E}^{\text {rns }}$ transport to the cell surface and cytoplasm was blocked. Although in those conditions N-glycosylation of CSFV glycoproteins and their dimerization was not affected and such low doses of tunicamycin were non-toxic to mammalian cells, they very effectively inhibited propagation of CSFV.

Concluding, although tunicamycin is toxic in higher doses, its antiviral effect should be thoroughly studied. Its less toxic, cheaper synthetic structural analogs could prove to be effective in fighting viral infections. This line of research should be further explored by examining the effect of tunicamycin and its derivatives on other epidemiologically important flaviviruses, especially on human hepatitis $\mathrm{C}$ virus. 


\section{Acknowledgements}

We thank Dr. Tomasz Stadejek from the National Veterinary Institute in Puławy (Poland) for the vaccine strain Cellpest of CSFV. This work was supported by the State Committee for Scientific Research (KBN, Poland) grant 2P04B 01226.

\section{REFERENCES}

Elbein AD (1987) Inhibitors of the biosynthesis and processing of N-linked oligosaccharide chains. Annu Rev Biochem 56: 497-534.

Frey CF, Bauhofer O, Ruggli N, Summerfield A, Hofmann MA, Tratschin JD (2006) Classical swine fever virus replicon particles lacking the $E^{\text {rns }}$ gene: a potential marker vaccine for intradermal application. Vet Res 37: 655-670.

Horikawa K, Oishi N, Nakagawa J, Kasai A, Hayakawa K, Hiramatsu N, Takano Y, Yokouchi M, Yao J, Kitamura M (2006) Novel potential of tunicamycin as an activator of the aryl hydrocarbon receptor-dioxin responsive element signaling pathway. FEBS Lett 580: 3721-3725.

Hulst MM, Moormann RJ (1997) Inhibition of pestivirus infection in cell culture by envelope proteins $\mathrm{E}(\mathrm{rns})$ and E2 of classical swine fever virus E(rns) and E2 interact with different receptors. J Gen Virol 78: 2779-2787.

Hulst MM, Himes G, Newbigin E, Moormann RJ (1994) Glycoprotein E2 of classical swine fever virus: expression in cells and identification as a ribonuclease. Virology 200: 558-565.

Imperiali B, O'Connor SE, Hendrickson T, Kellenberger C (1999) Chemistry and biology of asparagine-linked glycosylation. Pure Appl Chem 71: 777-787.

Indyk K, Olczak T, Ciuraszkiewicz J, Watorek W, Olczak M (2007) Analysis of individual azurocidin N-glycosylation sites in regard to its secretion by insect cells, susceptibility to proteolysis and antibacterial activity. Acta Biochim Polon 54: 567-573.

Jones J, Krag S, Betenbaugh MJ (2005) Controlling N-linked glycan site occupancy. Biochim Biophys Acta 1726: 121137.

Luckow VA, Lee SC, Barry GF, Olins PO (1993) Efficient generation of infectious recombinant baculoviruses by site-specific transposon-mediated insertion of foreign genes into a baculovirus genome propagated in Escherichia coli. J Virol 67: 4566-4579.

Leavitt R, Schlesinger S, Kornfeld S (1977) Tunicamycin inhibits glycosylation and multiplication of Sindibis and vesicular stomatitis viruses. J Virol 21: 375-385.

Maruo K, Nagata T, Yamamoto S, Nagai K, Yajima Y, Maruo S, Nishizaki T (2003) Tunicamycin inhibits NMDA and AMPA receptor responses independently of N-glycosylation. Brain Res 977: 294-297.

Mehta A, Zitzmann N, Rudd PM, Block TM, Dwek RA (1998) Alpha-glucosidase inhibitors as potential broad based anti-viral agents. FEBS Lett 430: 17-22.
Miller LK (1993) Baculoviruses: high level of expression in insect cells. Curr Opin Gen Devel 3: 97-101.

Pande AB, Carr V, Wong SA, Dalton K, Jones IM, McCauley JW Charleston B (2005) The glycosylation pattern of baculovirus expressed envelope protein E2 affects its ability to prevent infection with bovine viral diarrhoea virus. Virus Res 114: 54-62.

Parodi AJ (2000) Role of N-oligosaccharide endoplasmic reticulum processing reactions in glycoprotein folding and degradation. Biochem J 384: 1-13.

Risatti GR, Holinka LG, Fernandez Sainz I, Carrillo C, Lu Z, Borca MV (2007) N-linked glycosylation status of classical swine fever virus strain Brescia E2 glycoprotein influences virulence in swine. J Virol 81: 924-933.

Rumen T, Unger G, Strauss HJ, Thiel H (1993) Processing of the envelope glycoproteins of pestiviruses. J Virol 67: 3288-3294.

Scanlan CN, Offer J, Zitzmann N, Dwek RA (2007) Exploiting the defensive sugars of HIV-1 for drug and vaccine design. Nature 446: 1038-1045.

Schneider R, Unger G, Stark R, Schneider-Scherzer E, Thiel HJ (1993) Identification of a structural glycoprotein of an RNA virus as a ribonuclease. Science 261: 11691171.

Thiel HJ, Stark R, Weiland E, Rumenapf T, Meyers G (1991) Hog cholera virus: molecular composition of virions from a pestivirus. J Virol 65: 4705-4712.

Trombetta ES (2003) The contribution of N-glycans and their processing in the endoplasmatic reticulum to glycoprotein biosynthesis. Glycobiology 13: 77R-91R.

Tyborowska J, Bienkowska-Szewczyk K, Rychłowski M, van Oirschot JT, Rijsewijk FAM (2000) The extracellular part of glycoprotein $\mathrm{E}$ of bovine herpesvirus 1 is sufficient for complex formation with glycoprotein I but not for cell-to-cell spread. Arch Virol 145: 333-351.

Tyborowska J, Reszka N, Kochan G, Szewczyk B (2006) Formation of pseudorabies virus glycoprotein E/I complex in baculovirus recombinant system. Acta Virol 50: 169-174.

Wang Z, Nie Y, Wang P, Ding M, Deng H (2004) Characterization of classical swine fever virus entry by using pseudotyped viruses: E1 and E2 are sufficient to mediate viral entry. Virology 330: 332-341.

Wildish JM, Schneider R, Stark R, Weiland E, Meyers G, Thiel HJ (1996) RNase of classical swine fever virus: biochemical characterization and inhibition by virusneutralising antibodies. J Virol 73: 3404-3404.

Weiland E, Stark R, Haas B, Rumenapf T, Meyers G, Thiel HJ (1990) Pestivirus glycoprotein which induces neutralizing antibodies forms part of a disulfide-linked heterodimer. J Virol 64: 3563-3569.

Weiland F, Weiland E, Unger G, Saalmuller A, Thiel HJ. (1999) Localization of pestivirus envelope proteins $\mathrm{E}(\mathrm{rns})$ and E2 at the cell surface and on isolated particles. J Gen Virol 80: 1157-1165. 